\title{
Navigating Copyright in Electronic Theses and Dissertations
}

Gesina A. Phillips, MLIS, MA | Gumberg Library, Duquesne University

\section{Introduction}

Graduate students preparing electronic theses and dissertations (ETDs) encounter a broad range of questions related to copyright-both in terms of their use of copyrighted materials and their own status as copyrightholders. This project seeks to ascertain the extent to which these specific needs are addressed in published library literature, and to make recommendations to fill the gaps.

\section{Methods}

A survey of the literature related to copyright education by librarians-and in particular copyright education for graduate students working on theses and dissertationswas undertaken in order to ascertain the breadth of the published literature on this topic. Articles related to copyright education were examined in order to determine the extent to which they discussed copyright programs for students, whether or not they differentiated between undergraduate and graduate students, and if so, whether the unique needs of graduate students were discussed.
Aligning Copyright Education with the Graduate Student Timeline

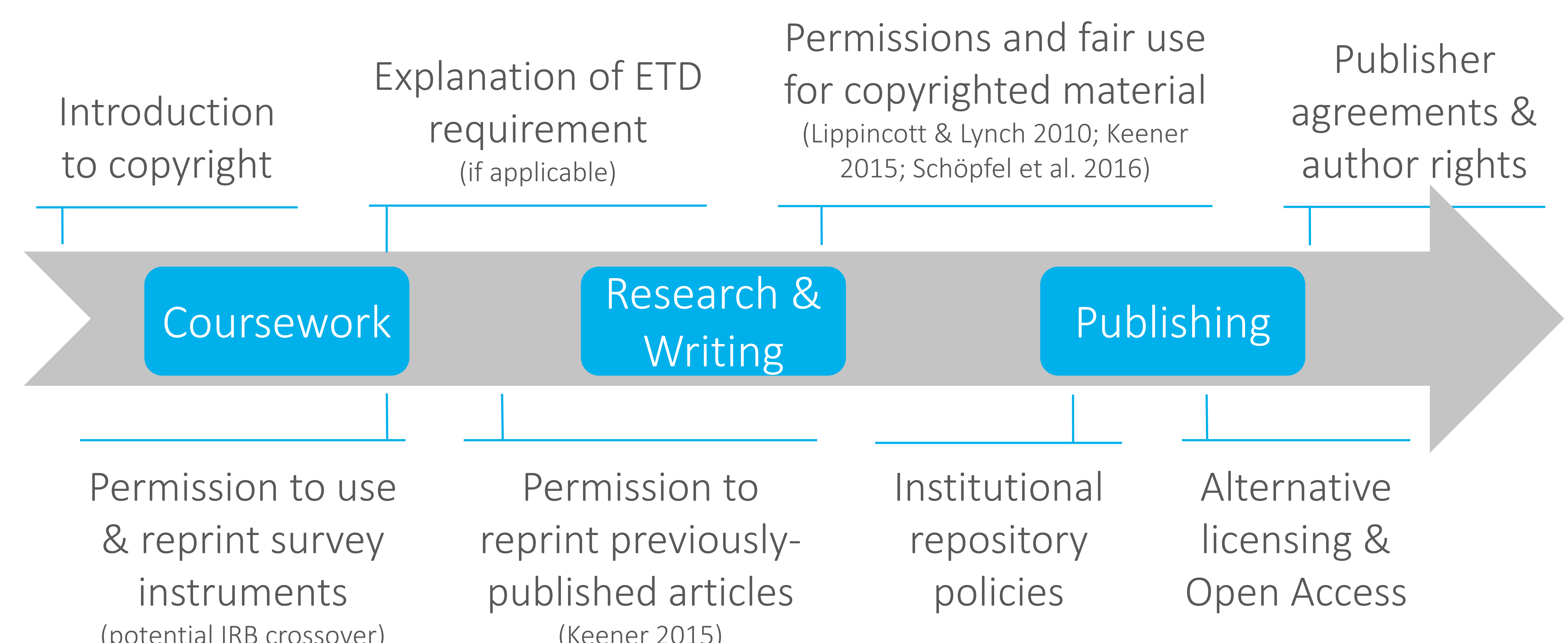

Several of the articles identified discussed the needs of graduate students. However, a more thorough examination of educational outreach to this population is called for. The diagram above aligns a generalized graduate student timeline with opportunities for copyright education scaled to the student's needs over time. The specific points of interaction are intentionally left vague in order to describe a process rather than a one-size-fits-all solution.

\section{Trends in the Literature}

\section{Student interaction with copyright is not the focus:}

- Ethical and legal use of content (Nilsson 2016, p. 80)

- Recipients of copyrighted information (Sims 2011)

Undergraduate and graduate students are not differentiated, but student interaction with copyright is explicitly considered:

- Connection between copyright and information literacy education for students (Cheng \& Winter 2014; Horava 2010)

Students included in a discussion of copyright education on campus more generally (Bull \& Eden 2014; Quartey 2007; Zerkee 2016)

- Student-held copyright (Conlogue \& Christianson 2016, p. 41)
Graduate students are discussed but not the focus:

- Graduate student copyright inquiries related to ETDs (Ravas 2016, p. 2)

Graduate student needs compared to those of faculty, including their interaction with publishing agreements (Ferullo 2011, p. 113)

- Stakeholder analysis identifies an opportunity related to a graduate student's ETD (ARL n.d., p. 5)

Graduate students are an area of specific focus:

- Use of copyrighted material in ETDs (Lippincott \& Lynch 2010; Keener 2015; Schöpfel et al. 2016)

Reuse of previously-authored articles (Keener 2015)

\section{Works Cited}

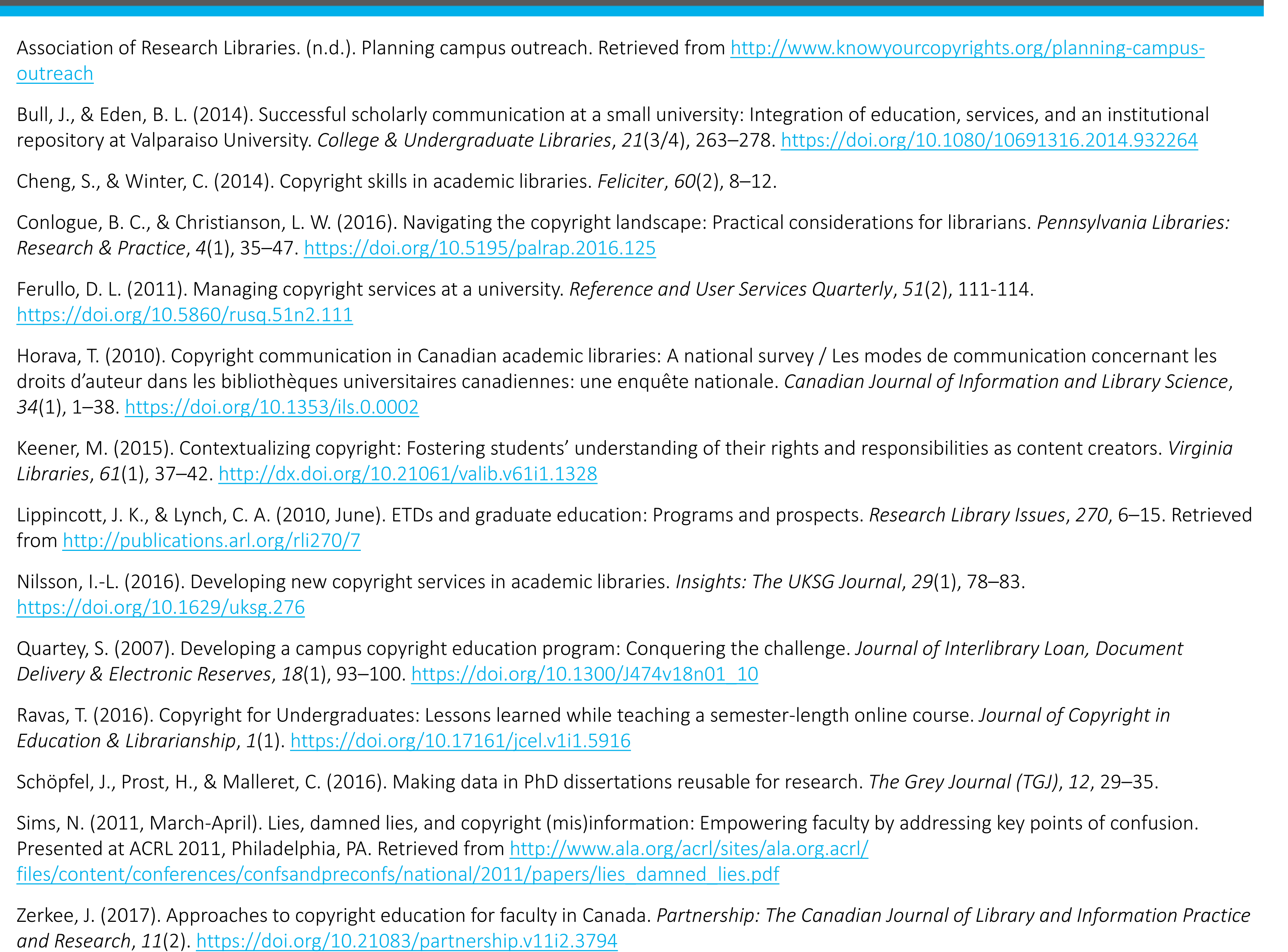

